\title{
Clinical Reasoning: A 53-year-old woman with headache and altered mental status
}

Kristyn M. Spera, MD, Christopher T. Doughty, MD, and Sashank Prasad, MD

Neurology ${ }^{\circledR}$ 2018;90:e1267-e1270. doi:10.1212/WNL.0000000000005260
Correspondence

Dr. Spera

kspera@partners.org

\section{Section 1}

A 53-year-old woman presented with headache and confusion. Three weeks prior, she experienced bifrontal thunderclap headache after lifting a laundry basket. There was photophobia but no nausea, emesis, sensorimotor complaints, autonomic features, or positional component. She was evaluated in the emergency department (ED). CT scan of the head was unremarkable, her headache improved spontaneously, and she was discharged. Within 2 weeks, thunderclap headache recurred and was accompanied by confusion. Her husband noted she forgot how to wash her hands and poured water into the toaster instead of the sink. At one point, she fell out of bed, was incontinent of urine, was unable to stand independently, and dropped things with her right hand. MRI of the brain was performed, which was reported as unremarkable but limited due to patient motion. The patient was prescribed topiramate, but headache and confusion persisted, so 4 days later her husband brought her to our ED for evaluation.

The patient had a history of hypertension, depression, chronic low back pain, and tobacco use. She had no history of headaches, nor was there family history of migraine. One month prior to presentation, she experienced cough, nasal congestion, and a perioral cold sore outbreak. On examination, she was afebrile, with a blood pressure of $107 / 55 \mathrm{~mm} \mathrm{Hg}$. She was somnolent, inattentive, and perseverative in speech. She demonstrated a right homonymous inferior quadrantanopia, simultanagnosia, left-right confusion, and inability to perform simple calculations. There was no papilledema. Strength and sensation were normal, but there was dysmetria in the left arm. Urine toxicology screen was positive for amphetamines and opiates.

Urinalysis, complete blood count, and comprehensive metabolic panel were normal.

\section{Questions for consideration:}

1. What is the differential diagnosis for this presentation of headache and confusion?

2. What diagnostic tests would be most helpful?

GO TO SECTION 2 


\section{Section 2}

The patient's recurrent thunderclap headaches, subacute encephalopathy, and focal neurologic deficits suggest an ominous etiology. The finding of simultanagnosia implicates bilateral occipito-parietal pathology, acalculia and left-right confusion suggest left parietal involvement, and dysmetria suggests cerebellar pathology. Multifocal infarcts could explain these deficits. The episode of falling, incontinence, and weakness could represent either seizure or a fall from impaired vision or gait. Given the report of negative CT and MRI, intracranial hemorrhage is unlikely. The differential should include infectious meningoencephalitis, intracranial malignancy (including lymphoma, carcinomatous meningitis, and metastatic disease), cerebral venous sinus thrombosis, cervical arterial dissection, and posterior reversible encephalopathy. Furthermore, vasculopathies such as reversible cerebral vasoconstriction syndrome (RCVS), druginduced vasculopathy, vasculitis due to systemic disorders, and primary angiitis of the CNS (PACNS) should be considered. ${ }^{1}$ Given recent upper respiratory infection and herpes labialis outbreak, postinfectious acute disseminated encephalomyelitis or infectious vasculitides should also be considered.

Given new focal examination findings and limited prior imaging, repeat neuroimaging is the most appropriate next diagnostic step to ensure there is no lesion exerting mass effect precluding lumbar puncture. Repeat MRI of the brain revealed acute and subacute infarcts within the bilateral occipital lobes and left cerebellar hemisphere. Magnetic resonance angiography was performed and demonstrated multifocal, irregular narrowing of multiple anterior and posterior circulation small- to medium-caliber vessels (figure, $\mathrm{A}-\mathrm{C}$ and $\mathrm{E}$ ). The following morning, the patient's mental status had improved dramatically without treatment, but an erythematous vesiculopapular rash had erupted under the left breast, extending in a dermatomal distribution over the lateral chest wall.

\section{IV acyclovir was started.}

\section{Questions for consideration:}

1. How do the MRI findings and rash eruption refine the differential diagnosis?

2. What additional diagnostic tests would you perform?

3. What additional historical information would be important to obtain?
Figure CT angiography
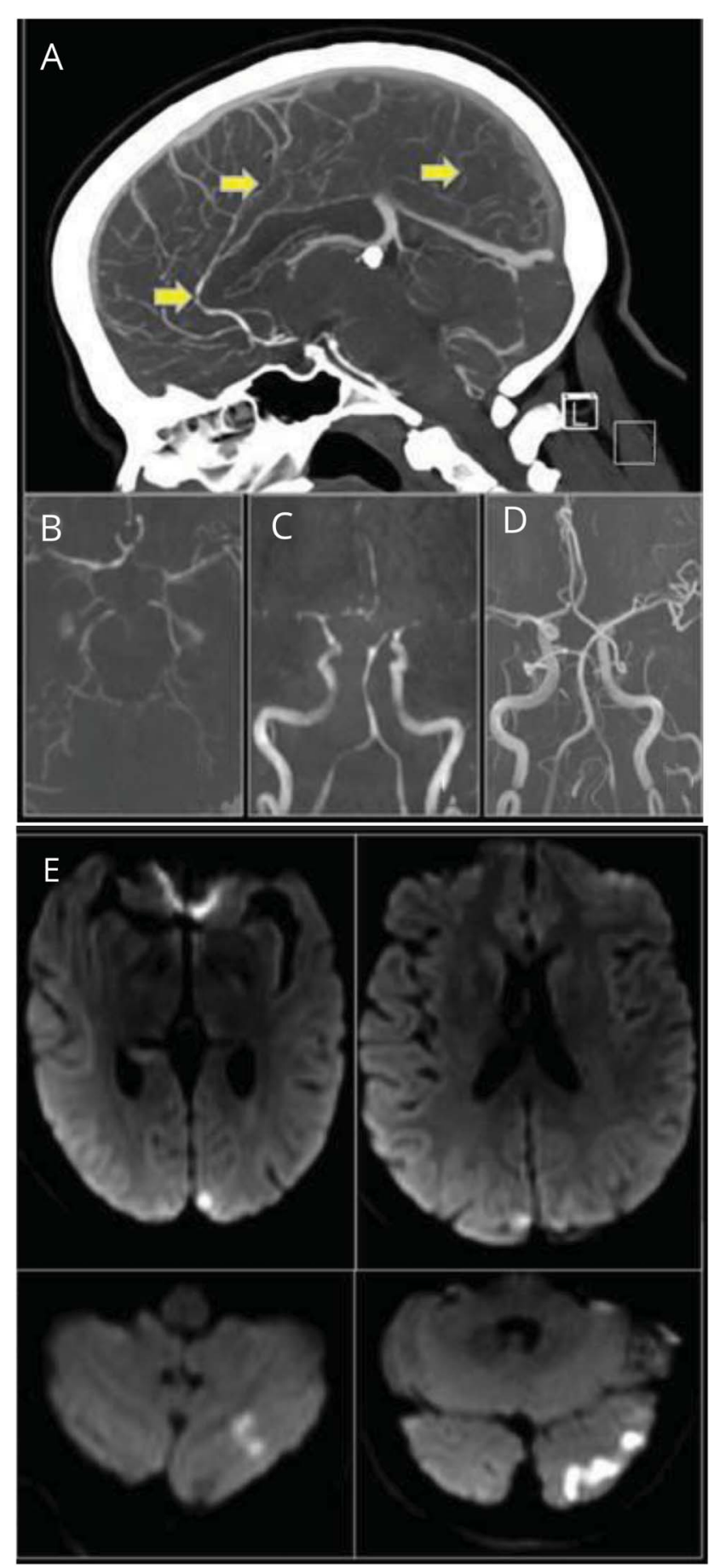

Sagittal (A) and axial (B) sections of the brain at time of initial presentation. There is diffuse attenuation and irregularity with multiple areas of narrowing (arrows) within the visualized small- and medium-caliber anterior cerebral artery (ACA) vessels (A), as well as the middle cerebral artery (MCA) and posterior cerebral artery (PCA) branches (B). (C) Magnetic resonance angiography (MRA) coronal sections of the brain at time of initial presentation demonstrate diffuse attenuation and irregularity of the bilateral MCA and PCA vasculature. (D) MRA of the brain coronal sections demonstrate resolution of vascular irregularity 3 months later. (E) MRI brain axial sections at time of presentation demonstrate multiple foci of restricted diffusion within the bilateral occipital lobes and left cerebellum. 


\section{Section 3}

The presence of multifocal infarcts and vessel narrowing is indicative of vasculopathy.

Possibilities include RCVS, PACNS, infectious vasculopathy, drug-induced vasculopathy, small- or medium-vessel systemic vasculitis with secondary nervous system involvement, and intravascular lymphoma. Lumbar puncture should be performed given the broad differential diagnosis. Our patient's CSF demonstrated 7 total nucleated cells $/ \mu \mathrm{L}$ in tube 1 and 4 cells $/ \mu \mathrm{L}$ in tube 4 with $69 \%-82 \%$ lymphocytic predominance, respectively, glucose of $97 \mathrm{mg} / \mathrm{dL}$, and total protein of $88 \mathrm{mg} / \mathrm{dL}$.

Given that the thoracic dermatomal rash was suspected to represent varicella-zoster virus (VZV) reactivation, VZV vasculopathy was strongly considered as a cause of the multifocal vascular abnormality and infarction. The diagnosis of VZV vasculopathy should be entertained in a patient with cutaneous findings consistent with shingles, angiographic evidence of vasculopathy, and CSF pleocytosis. VZV can cause a unifocal or multifocal vasculopathy and occurs in both immunocompetent and immunocompromised hosts, with vasculopathy usually developing weeks to months following rash outbreak. ${ }^{2}$ Estimated prevalence data come from literature in which VZV vasculopathy was discovered in immunocompromised patients postmortem, with prevalence ranging from $1.5 \%$ to $4.4 \% .^{3}$ True prevalence in immunocompetent patients is unknown as stroke in the elderly is often attributed to atheromatous disease and CSF analysis is not routinely performed. ${ }^{3,4}$ In this case, our pretest probability was initially moderate. The patient improved spontaneously prior to initiation of acyclovir, however, and both CSF VZV immunoglobulin G antibody testing - which is $93 \%$ sensitive and the preferred diagnostic test-and CSF VZV PCR were negative. Thus, acyclovir was stopped. Other infectious causes of CNS vasculitis to consider include Mycoplasma pneumoniae, HIV, hepatitis C virus (HCV), cytomegalovirus (CMV), Treponema pallidum, Borrelia burgdorferi, aspergillosis, or mucormycosis. ${ }^{5}$ Secondary vasculitis from systemic conditions_-including systemic vasculitides, antineutrophil cytoplasmic autoantibody (ANCA)-associated vasculitis, Behçet disease, lupus, rheumatoid arthritis, and Sjögren disease-can present similarly. ${ }^{5}$ It is critical to consider both RCVS and PACNS and to differentiate between the two, as the treatment for RCVS is supportive, while PACNS requires prompt immunosuppressive therapy. The headache of PACNS is chronically progressive, whereas $95 \%-100 \%$ of patients with RCVS experience thunderclap headache. Encephalopathy can be observed in both. ${ }^{1,6}$ Focal deficits at time of presentation are more commonly observed in RCVS, a disease occurring more often in women with a sex distribution of women:men ranging from 2.2:1 to $8.6: 1$. $^{1,6} \mathrm{Neu}-$ roimaging is abnormal in $90 \%-100 \%$ of patients with PACNS, compared to $12 \%-81 \%$ of patients with RCVS. CSF abnormalities are demonstrated in $80 \%-90 \%$ of PACNS cases and up to $60 \%$ of RCVS cases. ${ }^{1,6}$ Most helpful in distinguishing these two is the presence of a provocative factor, such as drug use or pregnancy, which is often seen in RCVS, while fever and elevated inflammatory markers can be seen in PACNS. ${ }^{6}$ The task of distinguishing RCVS or PACNS can be difficult and may ultimately require brain biopsy, the gold standard for PACNS diagnosis.

Additional laboratory data included erythrocyte sedimentation rate of $33 \mathrm{~mm} / \mathrm{h}$. Serum HIV-1/2 antibodies, Lyme ELISA, antinuclear antibody, dsDNA, Anti-Ro, Anti-La, ANCA, RF, and cryoglobulins were negative. Serum HCV antibody was reactive, but viral load and genotype testing were negative. Other negative studies included CSF culture, CMV PCR, and venereal disease research laboratory test. The patient's mental status improved, but headache persisted. Further history revealed that the patient had frequently been using nasal decongestants throughout the month preceding her presentation and had been on fluoxetine for years.

\section{Questions for consideration:}

1. What is your final diagnosis?

2. How would you treat this patient? 


\section{Section 4}

Our patient's mild CSF abnormalities ( $<10$ lymphocytes $/ \mu \mathrm{L}$ and protein $<100 \mathrm{mg} / \mathrm{dL}$ ) are nonspecific and can be seen in various vasculopathies as well as acute ischemic stroke and status epilepticus. ${ }^{6-8}$ It is therefore important to consider our patient's clinical presentation with thunderclap headache, encephalopathy, and improvement with supportive treatment in the setting of antidepressant and decongestant use. In light of these clinical clues, RCVS was suspected, and repeat neuroimaging was planned to assess for reversibility of the vasculopathy in 3 months. The diagnostic criteria for RCVS includes severe headache with or without focal deficits or seizures. The disease course is monophasic, without worsening 1 month after clinical onset. ${ }^{1,9,10}$ Segmental vasoconstriction of intracerebral arteries must be present with complete or substantial resolution within 3 months. CSF should demonstrate total protein $<100 \mathrm{mg} / \mathrm{dL}$ with $<15$ white blood cells $/ \mu \mathrm{L} .{ }^{1,9,10}$ Numerous medications have been implicated as potential triggers of RCVS, including nasal decongestants, nicotine, amphetamines, cocaine, cannabis, triptans, and selective serotonin reuptake inhibitors. ${ }^{1,9,10} \mathrm{We}$ considered brain biopsy to evaluate for PACNS, but this was deferred given rapid improvement in the absence of immunosuppressive therapy. In this case, index of suspicion was high for RCVS, and the decision to halt antiviral therapy and defer immunosuppression was guided by formal diagnostic criteria and observation of clinical course.

Treatment for RCVS is supportive, as the disease course is self-limiting, with the diagnosis requiring subsequent neuroimaging to document resolution of vasculopathy. ${ }^{1,9,10}$ Suspected culprit medications should be discontinued. Studies of calcium-channel blockade suggest benefit for headache relief but no benefit in resolving angiographic abnormalities. ${ }^{1,9,10}$ Glucocorticoids have been suggested to worsen clinical outcome in RCVS, adding to the importance of correctly distinguishing this entity from PACNS, which requires steroids. ${ }^{1,9,10}$ At follow-up 4 months after initial presentation, our patient was markedly improved with complete resolution of headache. Repeat magnetic resonance angiography revealed resolution of the vasculopathy (figure, D).

\section{Author contributions}

Dr. Spera: case report data review, analysis, and interpretation. Drs. Doughty and Prasad: critical revision of the manuscript for important intellectual content.

\section{Study funding}

No targeted funding reported.

\section{Disclosure}

The authors report no disclosures relevant to the manuscript. Go to Neurology.org/N for full disclosures.

\section{References}

1. Ducros A. Reversible cerebral vasoconstriction syndrome. Lancet Neurol 2012;11: 906-917.

2. Nagel MA, Cohrs RJ, Mahalingam R, et al. The varicella zoster virus vasculopathies: clinical, CSF, imaging, and virologic features. Neurology 2008;70:853-860.

3. Nagel MA, Mahalingam R, Cohrs RJ, et al. Virus vasculopathy and stroke: an underrecognized cause and treatment target. Infect Disord Drug Targets 2010;10: $105-111$.

4. Gilden D, Mahalingam R, Nagel MA, et al. The neurobiology of varicella zoster virus infection. Neuropathol Appl Neurobiol 2011;37:441-463.

5. Salvarani C, Brown $\mathrm{RD}$ Jr, Hunder GG. Adult primary central nervous system vasculitis. Lancet 2012;380.

6. Birnbaum J, Hellmann DB. Primary angiitis of the central nervous system. Arch Neurol 2009;66:704-709.

7. Ramirez-Lassepas M, Patrick BK. Cerebrospinal fluid cellular response in uncomplicated acute ischemic stroke. J Stroke Cerebrovasc Dis 1992;2:168-172.

8. Barry E, Hauser WA. Pleocytosis after status epilepticus. Arch Neurol 1994;51: 190-193.

9. Calabrese LH, Dodick DW, Schwedt TJ, et al. Narrative review: reversible cerebral vasoconstriction syndromes. Ann Intern Med 2007;146:34-44.

10. Singhal AB, Hajj-Ali RA, Topcuoglu MA, et al. Reversible cerebral vasoconstriction syndromes: analysis of 139 cases. Arch Neurol 2011;68:1005-1012. 


\section{Neurology}

Clinical Reasoning: A 53-year-old woman with headache and altered mental status Kristyn M. Spera, Christopher T. Doughty and Sashank Prasad

Neurology 2018;90; $1267-\mathrm{e} 1270$

DOI 10.1212/WNL.0000000000005260

This information is current as of April 2, 2018

\section{Updated Information \&} Services

References

Subspecialty Collections

Permissions \& Licensing

Reprints including high resolution figures, can be found at: http://n.neurology.org/content/90/14/e1267.full

This article cites 9 articles, 1 of which you can access for free at: http://n.neurology.org/content/90/14/e1267.full\#ref-list-1

This article, along with others on similar topics, appears in the following collection(s):

Infarction

http://n.neurology.org/cgi/collection/infarction Secondary headache disorders http://n.neurology.org/cgi/collection/secondary_headache_disorders

Information about reproducing this article in parts (figures,tables) or in its entirety can be found online at:

http://www.neurology.org/about/about_the_journal\#permissions

Information about ordering reprints can be found online:

http://n.neurology.org/subscribers/advertise

Neurology ${ }^{\circledR}$ is the official journal of the American Academy of Neurology. Published continuously since 1951, it is now a weekly with 48 issues per year. Copyright () 2018 American Academy of Neurology. All rights reserved. Print ISSN: 0028-3878. Online ISSN: 1526-632X.

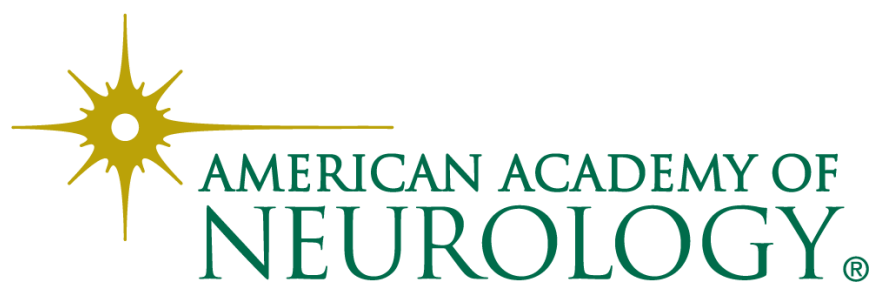

